American Journal of Biochemistry and Biotechnology 3 (3): 125-130, 2007

ISSN 1553-3468

(C) 2007 Science Publications

\title{
Bio-Safety Technology in Production of Bovine Herpesvirus Type 5 (BoHV-5) Using an Alternative Serum-Free Medium
}

\author{
${ }^{1}$ Tereza C. Cardoso, ${ }^{2}$ Heitor F. Ferrari, ${ }^{3}$ Maria Cecília R. Luvizotto and ${ }^{4}$ Clarice W. Arns \\ ${ }^{1}$ Laboratório de Virologia, Universidade Estadual Paulista, UNESP Campus de Araçatuba, Faculdade de \\ Odontologia, Curso de Medicina Veterinária, Araçatuba, SP-Brazil \\ ${ }^{2}$ Aluno de Pós-graduação Mestrado em Ciência Animal, Fellowship Fundação de Amparo à \\ Pesquisa do Estado de São Paulo, Brazil \\ ${ }^{3}$ Laboratório de Patologia Animal, Universidade Estadual Paulista, UNESP Campus de Araçatuba, \\ Faculdade de Odontologia, Curso de Medicina Veterinária, Araçatuba, SP-Brazil \\ ${ }^{4}$ Laboratório de Virologia Animal, Departamento de Microbiologia e Imunologia, Instituto de Biologia, \\ UNICAMP, Brazil
}

\begin{abstract}
The detection and growth of bovine herpes virus type 5 (BoHV-5) was evaluated in three different media without foetal bovine serum or animal protein by infecting three different cell lines. The OPTI-PRO, VP-SFM and RPMI 1640 media were supplemented by L-glutamine, antibiotics added by $5 \mu \mathrm{g}$ of insulin-like growth factor (IGF-I) and used to adapt CER, MDBK and CRIB cells in a statistic continuous culture system. The results obtained by CRIB and MDBK cells adaptation showed steady growth after $10^{\text {th }}$ passages in OPTI-PRO medium, $20^{\text {th }}$ passages in VP-SFM medium and $30^{\text {th }}$ passages in RPMI 1640 medium, respectively. The OPTI-PRO and RPMI 1640 media were not able to support CER growth, even supplemented by IGF-1 and present apoptotic cells at $72 \mathrm{~h}$ post-infection. The CER cells seeded after adaptation by $10^{\text {th }}$ passages in VP-SFM medium added by $5 \mu \mathrm{g} / 20 \mathrm{ml}$ of IGF- 1 growth factor revealed the best virus titres compared to MDBK and CRIB cell lines. It was concluded that CER, MDBK and CRIB cells infected by BoHV-5 serotype could be used for laboratory diagnosis propagated on much safer culture system of high biotechnology advances.
\end{abstract}

Key words: Bovine Herpesvirus, BoHV-5, CER cells, MDBK cells, CRIB cells, serum-free media

\section{INTRODUCTION}

Bovine Herpes virus type $5(\mathrm{BoHV}-5)$ is member of the family Herpesviridae, sub-family Alphaherpesvirinae and is primary etiological agent of non-suppurative meningoencephalitis that causes significant economic losses to beef cattle in South of America. Outbreaks of BoHV-5-associated encephalitis have been reported worldwide with mortality rate close to $100 \%$. In addition, bovine herpesvirus type 1 (BoHV-1) is one of the most important cattle pathogens, causing great economic losses to Brazilian cattle industry also ${ }^{[1-3]}$.

Recently, it was described the cross-protection conferred by BoHV-1 vaccine against BoHV-5 disease. The cross-protection theory is based upon rare occurrence of BoHV-5 associated disease in BoHV-1 endemic area or farms with intense vaccination schedules against BoHV-1 ${ }^{[4]}$. Otherwise, it has been showed that glycoprotein $\mathrm{E}$ is inefficient to produce cross protection between BoHV-1 and BoHV- $5^{[5]}$. In fact, the vaccine against BoHV-1 is routinely formulated by infection of MDBK (Madin Darby bovine kidney) cell line grown in Eagle Minimal Medium (MEM) supplemented by foetal bovine serum. Moreover, this culture system is also used to isolate clinical samples and to perform serum neutralization assays $^{[3,6,7]}$. Otherwise, it has been reported the efficacy of serum-free vaccine produced to BoHV-1 and bovine parainfluenza type $3^{[8]}$.

Foetal bovine serum (FBS) has traditionally been used in cell cultures for vaccine production and it is now widely recognize that FBS can carry heterogeneous contamination such as fungi, bacteria, viruses, microbial nucleic acids and more specially the prion of bovine spongiform encephalopathy (BSE $)^{[7-10]}$. It is important to emphasize that FBS can also contain bovine viral diarrhoea virus (BVDV), which is able to

Corresponding Author: Tereza. C. Cardoso, Departamento de Apoio, Produção e Saude Animal Curso de Medicina Veterinária Rua Clóvis Pestana, 793. 16.050-680 Araçatuba, SP, Brasil 
replicate in cultured cells from bovine species and often contaminate cells from other non-related species. For this purpose, an alternative culture system, classified as CRIB cells, was developed to avoid cross contamination with bovine viruses in the laboratory ${ }^{[6]}$. Moreover, CRIB cells has been reported to be resistant to BVDV infection in vivo derived from MDBK cells and obtained by selection and cloning of cells surviving infection by high cytolitic BVDV strain ${ }^{[6]}$. For instance, CER cells have been used frequently to isolate and, also propagate rabies virus ${ }^{[1]}$ and recently, described to support bovine syncytial respiratory virus ${ }^{[5]}$. Nevertheless, there is no report describing the CER use on BoHV virus infection until now.

The present study was conducted to apply an alternative technology of serum-free culture system to support BoHV-5 infection and propagation using the CER, MDBK and CRIB cell line as a safe way for virus propagation and isolation.

\section{MATERIALS AND METHODS}

Cells and media: The following cells line were used: chicken embryo related cells (CER), a cell hybrid derived from chicken embryo fibroblast and BHK-21 (baby hamster kidney cells clone 21, ATCC CCL-10); MDBK (Madin-Darby bovine kidney cells, ATCC CCL-22) and CRIB cells, which are derived from MDBK and kindly provided by Dr Clarice W Arns (Universidade Estadual de Campinas, UNICAMP, Laboratório de Virologia Animal). The cells were grown in flasks of $75 \mathrm{~cm}^{3}$ at $37^{\circ} \mathrm{C}$, using an initial concentration of $3.5 \times 10^{4}$ cells $/ \mathrm{ml}$ in a traditional Eagle's minimal essential medium (E-MEM) plus antibiotics and $10 \%$ of irradiated bovine foetal serum (GIBCO-BRL). Monolayers were grown to $87 \%$ of cell confluence and then the cells were transferred to a serum and protein free culture. The media used were: OPTI-PRO ${ }^{\circledR}$ (GIBCO-BRL); VP-SFM ${ }^{\circledR}$ (GIBCOBRL) and Advanced RPMI 1460 (GIBCO-BRL) following the manufacture's recommendations. The adaptation to a serum/protein free media was done directly switching the traditional medium to the new ones.

Mycoplasma and exogenous viruses examination: The monolayers were tested for Mycoplasma using the general culturing method, described as a combination of liquid and agar media for reported by previous studies. The exogenous bovine viruses, as bovine viral diarrhoea virus (BVDV) and bovine respiratory syncytial virus (BRSV) were tested according to previous studies ${ }^{[12]}$.
Insulin-like growth factor-1 supplementation: After the cells were adapted to the different media described before, the respective monolayers were rinsed twice with fresh medium and replenished with OPTI-PRO, VP-SFM and RPMI 1640 added by $5 \mu \mathrm{g} / 20 \mathrm{ml}$ of Insulin - Like Growth Factor-I (IGFI) ${ }^{[13]}$.

Annexin V staining: Translocation of phosphatidylserine to the external surface of apoptotic cell membrane was examined by staining of fixed samples for infected and control cells with antiannexin-V-FITC conjugated mAb. The images were analyzed by immunofluorescence microscope and the images recorded.

Virus infection and propagation: After adaptation in the new system culture, the respective monolayers were infected by 20 clinical samples of BoHV- 5 collected from an outbreak in 2005 (São Paulo State-Brazil), previously characterized by immuperoxidase monolayer assay and PCR, gently supplied by Laboratório Patologia, UNESP-Araçatuba. Adsorption was allowed for 1 hour and half at $37^{\circ} \mathrm{C}$. Subsequently the medium was replaced and the flasks were incubated at $37^{\circ} \mathrm{C}$ during 5 days. The viruses were submitted to infection three times in each cell line. Titration results were confirmed by observation of cytopathic effect (CPE) appearance, describe as being syncytial formation ${ }^{[3]}$. The respective titers were calculated by SpearmannKärber method and expressed as the $\log _{10}$ tissue culture infective dose per $50 \quad\left(\mathrm{TCID}_{50} / 50 \mu \mathrm{l}\right)$ described previously.

Growth characteristics: Growth characteristics of BoHV-5 on CER, MDBK and CRIB cells were assayed in a multiplicity of infection (m.o.i) 1, which had been previously determined for both cells. Adsorption was allowed for 1 hour and half at $37^{\circ} \mathrm{C}$ and the inoculum removed just after. The respective monolayer were then washed with fresh medium and incubated for different time post-infection $(0,4,8,24,48,72$ and $120 \mathrm{~h}$ postinfection, p.i). The supernatant from respective infected monolayers were collected and assayed for BoHV-5 detection by virus neutralization assay. All the experiments were performed in duplicate and the infectious virus calculated according to SpearmannKärber method as described before ${ }^{[5]}$.

Statistical analysis: Statistical analysis was performed using the Student's $t$-test and analysis of variance (ANOVA); the least significant difference at $p=0.05$ was determined ${ }^{[5]}$. 


\section{RESULTS}

Cell adaptation to serum free media: All the cell lines analyzed here MDBK, CER and CRIB types, were well adapted to VP-SFM serum free medium. However, only CER cell line was not adapted to OPTI-PRO and VP-SFM media, even after an increase IGF-I concentration (results not shown). The morphological characteristics were preserved as shown on Fig. 1D, F and $\mathrm{H}$ and the typical cytopathic effect was visualized of all mammalian cells adapted to VP-SFM medium and infected by BoHV-5 (Fig. 1E, G and I) at $120 \mathrm{~h}$ post-infection. Monolayer confluence was determined by visual evaluation as illustrated in Fig. 1A, B and C for MDBK cells, $10 \%, 30 \%$ and $80 \%$ of confluence, respectively. No Mycoplasma and no exogenous virus could be detected in this culture system (data not shown). As shown in Fig. 1A, B and C, the MDBK monolayer morphology was not affected in respect to confluence and adherence characteristic. After cell adaptation, the VP-SFM medium plus IGF-I was the only substrate capable to support all the cell lines studied here (Fig. 1D, F and H). The respective CPE was the same observed by others studies, using the conventional MDBK cultured system ${ }^{[1,2,4,6]}$ as shown in Fig. 1E, G and I for MDBK, CER and CRIB cells, respectively. In fact, there are many advantages in using serum-free culture systems; first it has been suggested that cells cultured without serum/protein seems to be more favourable for viral infection than cultured by using the serum-supplemented medium; second bovine serum may contains viral inhibitors, such proteases, that decreases the virus stability; and third bovine serum may contains exogenous pathogens and also prions ${ }^{[7,13 \text {, }}$ $14,15]$.

Virus titres: Both cell lines were susceptible to infection after adapted to a serum-free media culture. However, the addition of IGF-1 increases the monolayer viability, which had allowed more virus production after 120 post-infection. Even the CPE has started $6 \mathrm{~h}$ p.i. for all cells analyzed; it was possible to maintain viable $30 \%$ of the respective monolayers by addition of IGF-I to the media with no replacement with fresh medium at $120 \mathrm{~h}$ p.i. (Fig. 1D, F and H). Recently, it has been shown that insulin like growth factor -I (IGF-I) can replace insulin as the main mitogenic factor in serum free cultures. Besides, IGF-I has an antiapopotic activity, which can protecting cultures fro diverse death-inducing stimuli through interaction with its receptor ${ }^{[13]}$. In the resent work, the use of IGF-I, at a unique concentration in all media applied, confers viable cells at $120 \mathrm{~h}$ pos-infection

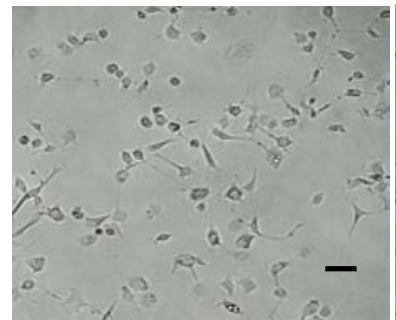

(A)

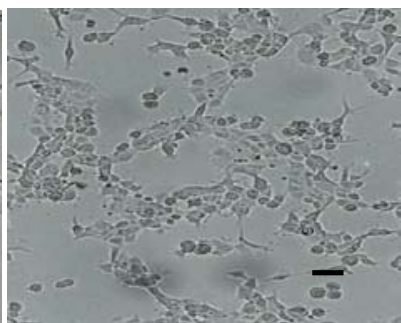

(B)
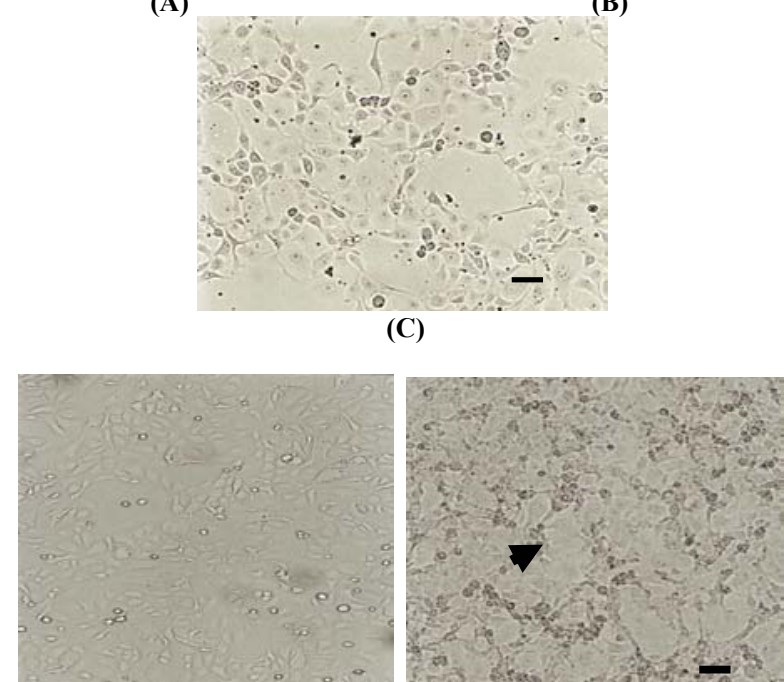

(D)

(E)

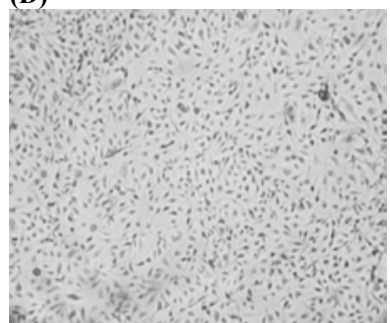

(F)
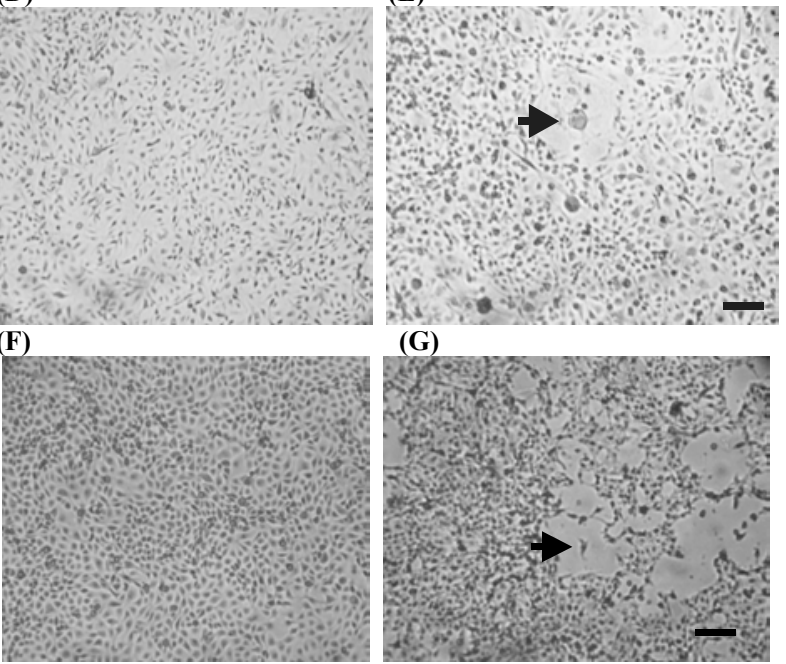

(H)

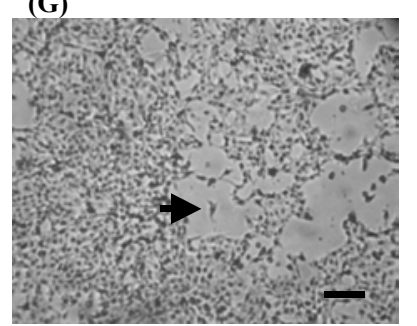

(I)

Fig. 1: Characteristic of MDBK monolayer grown on VP-SFM medium; (A) $10 \%$ of monolayer confluence; (B) $30 \%$ of monolayer confluence; (C) $80 \%$ of monolayer confluence; (D) Non-infected MDBK monolayer at $120 \mathrm{~h}$ of culture on VP-SFM medium; (E) Infected MDBK monolayer at $120 \mathrm{~h}$ p.i. (narrow CPE); (F) Non-infected CER monolayer at $120 \mathrm{~h}$ of culture on VP-SFM medium; (G)Infected CER monolayer at $120 \mathrm{~h}$ p.i. (narrow CPE); (H) Non-infected CRIB monolayer at $120 \mathrm{~h}$ of culture on VP-SFM medium; (I) Infected CRIB monolayer at 120 p.i. (narrow CPE). Bar $30 \mu \mathrm{m}$ 


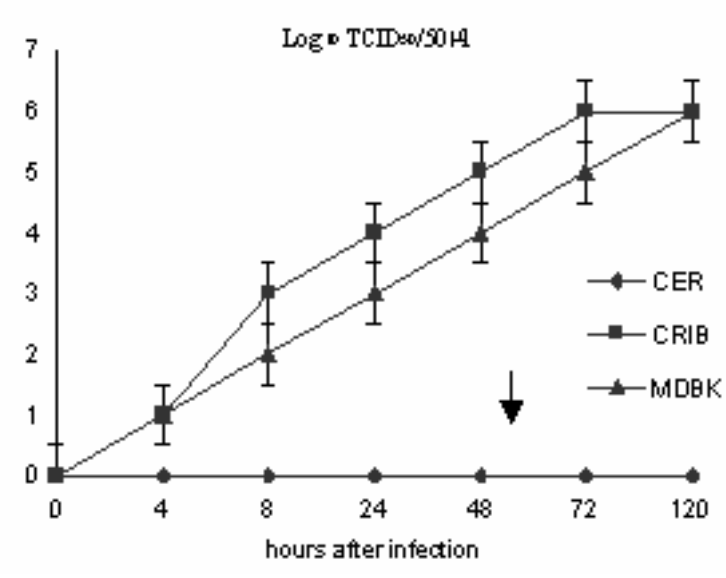

(1)

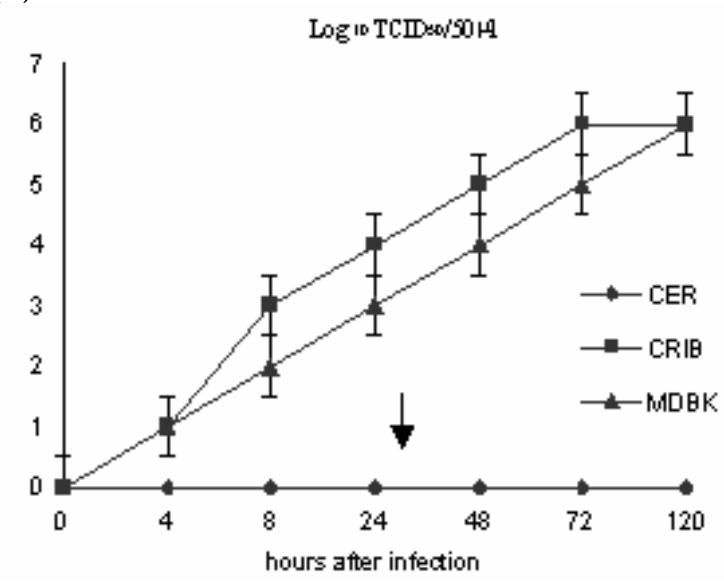

(B)

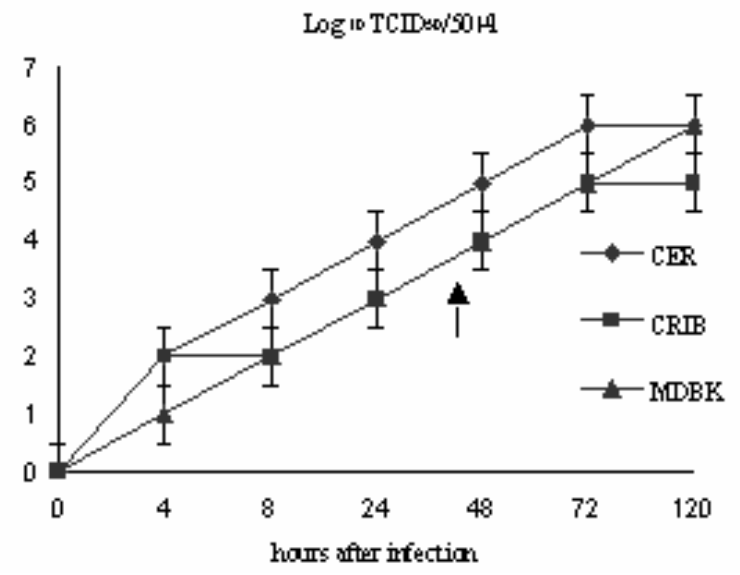

(C)

Fig. 2: Comparison of BoHV-5 growth characteristics in MDBK, CER and CRIB cell using the OPTI-PRO medium (A), RPMI-1640 medium (B) and VP-SFM medium (C). Each value is the mean of three infected wells with the respective standard deviation bars, at different time intervals (hour post-infection)
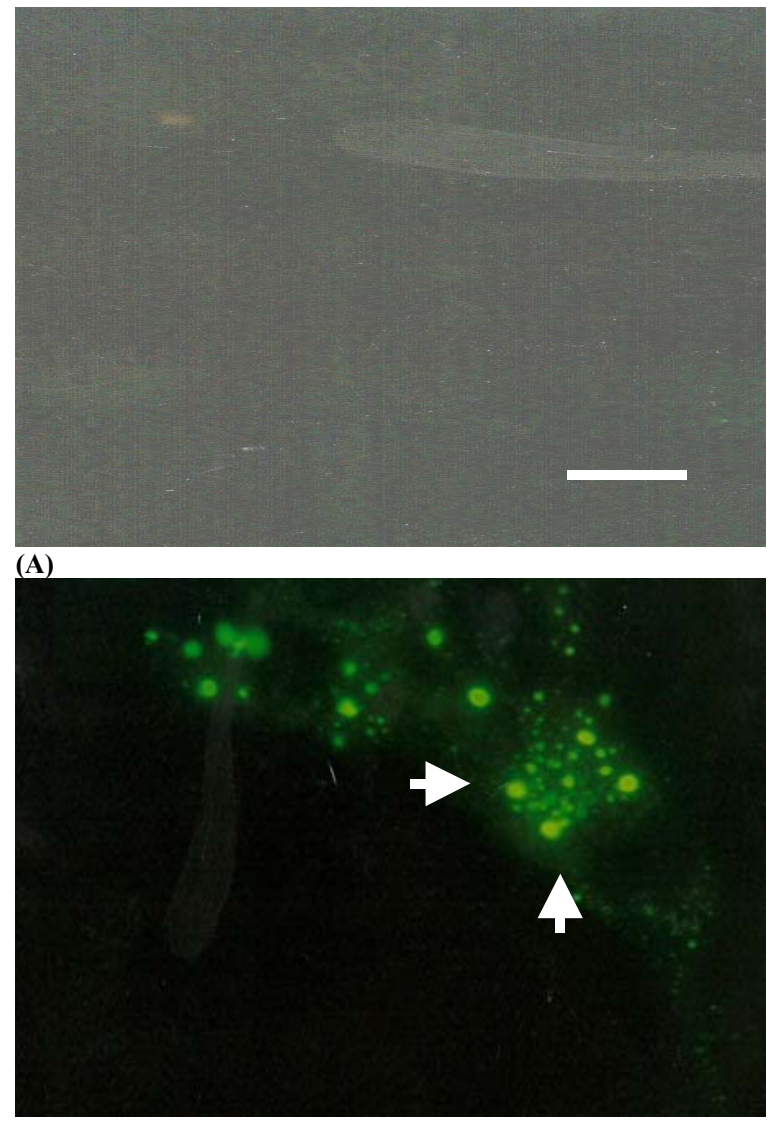

(B)

Fig. 3: Annexin V staining pattern observed after $72 \mathrm{~h}$ postinfection for CER, MDBK and CRIB cells (A) Positive intranuclear signal; (B) Negative control. (narrow showing the positive signal). Bar $=30 \mu \mathrm{m}$

(Fig. 2A, B and C). To our knowledge, this is the first time demonstration of an addition of IGF-I in commercial media, for supporting MDBK, CER and CRIB cells. According to other studies, the IGF-I supplementation can confer survivability to Chinese Hamster Ovary Cells (CHO) but does not stimulate cell proliferation and is insufficient for growth in serumfree medium unless supplemented with transferring ${ }^{[13]}$. However, this phenomena, was not evaluated in this study.

Growth characteristics and apoptosis: One-step growth curves of the BoHV-5 strain in MDBK, CER and CRIB cells revealed no significant differences $(p=0.89664)$ in the infectious virus titres from 0 to 120 $\mathrm{h}$ post-infection in VP-SFM media plus IGF-I (Fig. 2C). However, only MDBK and CRIB were able to growth in OPTI-PRO and RPMI 1640 media (Fig. 2A and B), producing titre of $1 \log _{10} \mathrm{TCID}_{50}$ lower comparing to 
CER cells grown in VP-SFM added by IGF-I. The CER cells, considered non-permissive cell line, could be infected by BoHV-5, under growth on VP-SFM plus IGF-I medium, produced titres of 1 Log $10 \mathrm{TCID}_{50}$ higher than permissive cells, MDBK and CRIB (Fig. 2C). As demonstrated, the cells presented signals of apoptosis at $72 \mathrm{~h}$ post-infection, which did not interfered with virus production (Fig. 3A and B). Afterwards, the importance of BoHV growth behaviour in a nonpermissive system has been mentioned as a viable alternative culture system, because it allows for the analysis of fine details from particular step where the growth is arrested ${ }^{[4,14]}$. In this aspect, it was also demonstrated the ability of CER cells support bovine respiratory syncytial virus infection ${ }^{[5]}$. In fact, the present work do not evaluated the convention culture system used serum supplementation to make a parallel of cell proliferation. However, the commercial VP-SFM was the only medium applied successfully in producing virus titres in all systems analyzed. This same medium was used to produce rabies virus vaccine and demonstrated satisfactory virus particles production on microcarriers system, however it was not used the IGFI supplementation ${ }^{[14]}$. In the other hand, the RPMI 1640 medium described as suitable to MDCK cells and canine virus vaccines was also efficient to support BoHV 5 infection in MDBK and CRIB cells in the present study ${ }^{[12]}$.

\section{CONCLUSION}

In addition to primary and diploid cells, continuous cell lines have been accepted for the use in the production of viral vaccines for human and there have been a few industrial-scale productions of virus entirely using a serum/protein free process. Moreover, the use of cell culture is increasing exponentially and new in vitro alternatives are constantly being developed. Herein, VP-SFM medium was suitable for the production of BoHV-5 from CER cell culture. In addition, the MDBK and CRIB cells, were well adapted to serum-free media applied here, accomplished by desirable production of virus infective particles. Finally, this system is an alterative for the development of a bioprocess for the safe vaccines and also, biological in vitro methodologies for bovine Herpesvirus studies.

\section{REFERENCES}

1. Delhon, G., M.P. Moraes, Z. Lu, C.L. Afonso, E.F. Flores, R. Weiblen, G.F. Kutish and D.L. Rock, 2003. Genome of Bovine Herpesvirus 5. J. Virol., 77: 10339-10347.
2. Diel, D.G., S.R. Almeida, M.C.S. Brum, R. Dezengrini, R. Wieben and E.F. Flores, 2007. Acute and latent infection by bovine herpesvirus type 5 in experimentally infected goats. Vet. Microbiol., doi:10.1016/j.vetmic.2006.12.019.

3. Silva, A.D., F.R. Spilki, A.C. Franco, P.A. Esteves, S.O. Hübner, D. Driemeier, A.P. Oliveira, F. Rijsewijk and P.M. Roehe, 2006. Vaccination with a gE-negative bovine herpesvirus type 1 vaccine confers insufficient protection to a bovine herpesvirus type 5. Vaccine, 24: 3313-3320.

4. Del Médico Zajac, M.P., M. Puntel, P.I. Zamorano, A.M. Sadir and S.A. Romera, B., 2006. BHV-1 vaccine induces cross-protection against BHV-5 disease in cattle. Res. Vet. Sci., 81:327-334.

5. Spilki, F.R., R.S. Almeida, J. Campalans and C.W. Arns, 2006. Susceptibility of different cell lines to infection with bovine respiratory syncytial virus. J. Virol. Meth., 131:130-133.

6. Flores, E.F. and R.O. Donis, 1995. Isolation of a mutant MDBK cell line resistant to bovine viral diarrhea virus infection due to a block in viral entry. Virology, 208: 565-575.

7. Merten, O.W. 2002. Development of serum-free media for cell growth production of viruses/viral vaccines-Safety issues of animal productus used in serum-free media. In: Hendriksen C., D. Sesardic, K. Cussler, Editors. Advancing science and elimination of the use of laboratory animals for development and control of vaccines and hormones. Dev. Biol. Basel, Karger, 111: 233-257.

8. Makoschey, B., J.R. Patel and P.T.J.A. van Gelder, 2002. Serum-free produced bovine herpesvirus type -1 and bovine parainfluenza type 3 virus vaccines are efficacious and safe. Cytotechnology, 39: 139-145.

9. Butler, M., A. Burgener, M. Patrick, M. Berry, D. Moffatt, N. Huzel, N. Barnabé and K. Coombs, 2000. Application of a serum free medium for growth of vero cells and production of Reovirus. Biotech. Prog., 16: 854-858.

10. Cardoso, T.C., M.C.B. Teixeira, N. Fachin, T.L. Camargo, D.E. Gomes, A.C.O. Junior and B. Anselmo, 2005. Evaluation of serum and animal free media for the production of infectious bronchitis virus (M41) strain in a continuous cell line. ALTEX, 3:152-156.

11. Cardoso, T.C., L.H. Queiroz-Silva, S.E. Silva, A. Albas, P.E. Pardo, A.H. Tanaka, L.B. Cossy and S.H.V. Perri, 2006. Chicken related (CER) cell line for quantification of rabies neutralizing antibody by fluorescent focus inhibition test. Biologicals, 34: 29-32. 
12. Mochizuki, M., 2006. Growth characteristics of canine pathogenic viruses in MDCK cells cultured in RPMI 1640 medium without animal protein. Vaccine, 24: 1744-1748.

13. Sunstrom, N.A.S., R.D. Gay, D.C. Wong, N.A. Kitchen, L. DeBoer and P.P. Gray, 2000. InsulinLike Growth Factor-I and transferring mediate growth and survival of Chinese hamster ovary cells. Biotech. Prog.,16:698-702.

14. Frazzati-Gallina, N. M., R.L. Paoli, R.M. MourãoFunches, S.A.C. Jorge and C.A. Pereira, 2001. Higher production of rabies virus in serum-free medium cell cultures on microcarriers. J. Biotech., 92: 67-72.
15. Murata, T., Y. Takashima, X. Xuan and Otsuka. 1999. Growth behavior of bovine herpesvirus-1 in permissive and semi-permissive cells. Virus Res., 61: 29-41.

16. Genzel, Y., J.B. Ritter, S. König, R. Alt and U. Reichl, 2005. Substitution of glutamine by pyruvate to reduce ammonia formation and growth inhibition of mammalian cells. Biotech. Prog., 21: 58-69. 